\title{
Contribution of sleep to memory consolidation
}

\section{Anahita Shaffii-Le Bourdiec, Vincenzo Muto, Laura Mascetti, Ariane Foret, Luca Matarazzo, Caroline Kussé \& Pierre Maquet ${ }^{\dagger}$ \\ †Author for correspondence: Cyclotron Research Centre (B30), University of Liège, Allée du 6 Août, 4000 Liège, Belgium n Tel.: +324366 3687 m. Fax: +32 43662946 m pmaquet@ulg.ac.be}

The contribution of sleep to memory processing is being characterized at increasingly detailed levels. At a behavioral level, better performance at retrieval is usually observed after sleep, relative to a period of wakefulness. At a brainsystems level, functional neuroimaging techniques have demonstrated that the distribution of regional brain activity is influenced by previous waking experience. At present, the selective effects of sleep components, such as slow waves or spindles are being characterized. These effects are framed in terms of neural firing patterns and also in terms of the molecular mechanisms underpinning the effects of sleep on brain plasticity. Collectively, the available data indicate a positive influence of sleep on memory consolidation.

A growing body of evidence indicates that sleep promotes memory consolidation; the protracted process by which fresh, labile memories are reorganized into stable memories [1]. Although the first evidence for this effect was collected more than a century ago [2], the potential underlying neural mechanisms are only just beginning to be conceptualized and characterized experimentally.

Memory consolidation is a hackneyed expression that may take different meanings. At the cellular level, consolidation is often framed in terms of long-term experience-dependent changes in neural responsiveness, usually resulting from modifications in synaptic strength (Figure 1) [3-19]. At the systems level, consolidation relates to the progressive reorganization of memories within brain circuits [20-21]. From a behavioral perspective, consolidation refers to an improvement of performance between practice sessions or a reduction of vulnerability of a memory trace after the acquisition of a novel skill [22-23], although other phenomena such as automatization [24-25] or generalization [26] might also be considered as behavioral markers of memory consolidation (Figure 1).

It is therefore not surprising that the effects of sleep on memory consolidation were reported at various levels of description. The early studies assessed the effects of sleep on different memory systems at the behavioral level. They contrasted the influence of non-rapid eye movement sleep (NREMS) with rapid eye movement sleep (REMS) on declarative and procedural memories, respectively. As the understanding of the effects of sleep on memory consolidation progressed, the hypotheses were increasingly framed in terms of the neural processes occurring during
NREMS or REMS, and specifically, those associated with phasic events such as slow waves, spindles or phasic REMS.

This paper is organized into five sections. The first section summarizes the key findings of behavioral studies that suggest an effect of sleep on memory. Earlier reviews have already covered these results in detail [27-31]. The present article highlights recent data that call for a reappraisal of these effects that, although indisputable, seem quantitatively modest. The article also emphasizes the higher sensitivity of neuroimaging and neurophysiological measures in characterizing the effects of sleep on memory. The following sections review the two main hypotheses that are currently being tested, namely the homeostatic synaptic downscaling and the sleep-dependent systems-level consolidation. The final two sections emphasize the intervention of post-training REMs and wakefulness in memory processing.

\section{Behavioral effects}

The recognition of different memory systems helped to characterize the effects of sleep on memory consolidation (Figure 2). On the procedural side, spontaneous gains in performance in a motor sequence learning task were observed between initial training and later testing, specifically if the interval included sleep rather than wakefulness [32-33]. As these gains in performance emerged without further practice, it suggested that an 'offline' processing of motormemory was taking place during sleep. The spontaneous enhancement of procedural abilities appeared to depend primarily on REMS. Indeed, the enhanced performance in procedural learning tasks was observed when sleep was allowed

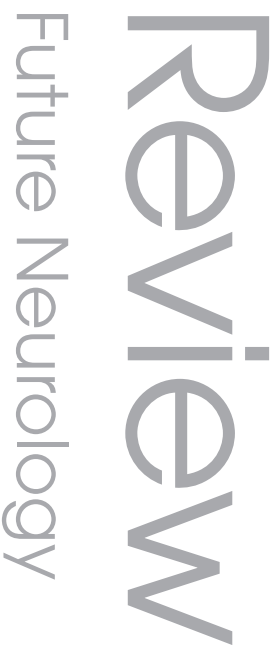

\section{Keywords}

a behavioral task = memory consolidation = neural processes $=$ neuroimaging - sleep

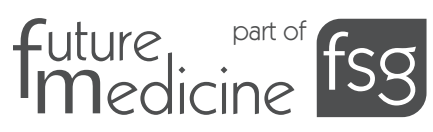




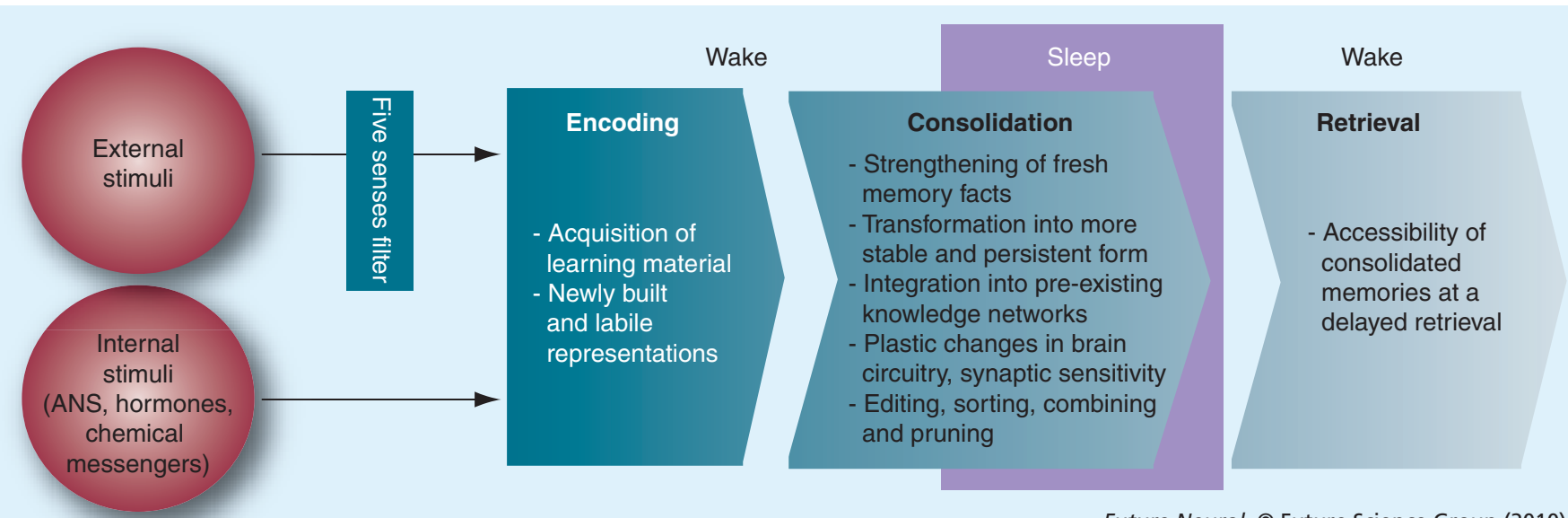

Future Neurol. @ Future Science Group (2010)

Figure 1. Memory is usually conceived to evolve in three distinct steps: encoding, consolidation and retrieval. Memory consolidation would occur covertly during both wakefulness and sleep. The objective now is to specify what are the conditions selectively present during sleep that promote memory consolidation.

ANS: Autonomic nervous system.

during the REMS-rich second part of the night rather than during the deep NREMS-rich first half [34-35]. Likewise, perceptual visual learning (e.g., texture discrimination tasks, see Box 1), involving a different procedural learning process, was demonstrated to be sensitive to REMS deprivation [36].

On the declarative side, despite early controversial results [37-40], declarative memory was also shown to be better preserved when sleep occurs immediately after encoding [41], and seems to benefit primarily from NREMS; word-pair associates are better retained if sleep is allowed during the first part of the night (rich in deep NREMS) rather than in the second portion of the night [35]. If olfactory cues are presented during a spatial source memory task and again delivered during subsequent NREMS, memory performance is enhanced during subsequent retrieval [42]. The same protocol has no effect for a procedural task such as the finger-tapping task (FTT) [42].

These results were compatible with the 'dual process' hypothesis, which claims that NREMS and REMS are primarily involved in the consolidation of declarative and procedural memories, respectively. However, this theory cannot easily account for data demonstrating, for instance, that procedural learning also benefits from NREMS-rich early night sleep [43-45]. The

\begin{tabular}{|c|c|c|c|}
\hline \multicolumn{2}{|c|}{ Declarative } & \multicolumn{2}{|c|}{ Nondeclarative } \\
\hline $\begin{array}{l}\text { Behavioral: } \\
\text { verbal paired } \\
\text { associate }\end{array}$ & $\begin{array}{l}\text { - Conscious } \\
\text { - Based on facts } \\
\text { - Flexible } \\
\text { - Readily acquired during } \\
\text { relatively few exposures } \\
\text { to events or facts }\end{array}$ & $\begin{array}{l}\text { - Non-conscious } \\
\text { - Less flexible } \\
\text { - Requires much longer } \\
\text { exposure and repetition } \\
\text { of actions }\end{array}$ & $\begin{array}{l}\text { Motor memory: } \\
\text { FTT; SRTT; }\end{array}$ \\
\hline $\begin{array}{l}\text { learning tasks } \\
\text { (i.e., word-pairs } \\
\text { and cued-recall; } \\
\text { nonsense syllables; } \\
\text { objects location; } \\
\text { short stories; } \\
\text { and word lists) }\end{array}$ & $\begin{array}{l}\text { Episodic } \\
\text { - Events of individual's } \\
\text { past (e.g., spatio-temporal } \\
\text { recollection) } \\
\text { Semantic } \\
\text { - General knowledge } \\
\text { not related to events } \\
\text { (but related to facts) }\end{array}$ & $\begin{array}{l}\text { Procedural } \\
\text { - Learning of skills } \\
\text { - Habits } \\
\text { - Actions } \\
\text { Implicit } \\
\text { - Exposure } \\
\text { - Perceptual learning } \\
\text { - Priming }\end{array}$ & $\begin{array}{l}\text { visual texture } \\
\text { discrimination; } \\
\text { sensory skills; } \\
\text { mirror tracing; } \\
\text { others: visuo-motor } \\
\text { discrimination }\end{array}$ \\
\hline
\end{tabular}

Figure 2. Memory is classically divided into two main groups involving different learning tasks.

FTT: Finger tapping task; SRTT: Serial reaction time task. 


\section{- Word-pair associate}

- Subjects are asked to learn lists of visually presented pairs of words by usually forming a mental image of both objects.

- During the recall sessions, all previously learned words are tested. Subjects are presented with the first word of each pair. They are instructed to remember the second word with the help of the mental picture they imagined previously.

- Navigation

- In experimental conditions, navigation is usually conducted in a color 3D first-person view of the environment, which consists of various streets with distinctive walls, objects, sounds and background music and in which volunteers navigate using a joystick to control their moves.

- Finger-tapping task

- The finger-tapping task is a common motor sequence learning task in which participants have to produce an explicitly known five-element finger sequence on a keyboard, with their left non-dominant hand.

- Serial reaction time task

- In a serial reaction time task, participants face a computer screen where permanent position markers are displayed. A keyboard with spatially compatible response keys is within reach of the right hand. Subjects are asked to react as quickly and accurately as possible to the appearance of a stimulus below one of the markers by pressing the spatially corresponding key. Unknown to the subjects, the sequence of the stimulus positions is not random but either fixed (deterministic) or generated based on a probabilistic finite-state grammar that defines logical transitions between successive trials.

- Serial oculo-motor reaction time task

- Participants have to visually track a dot that, at any point in time, is displayed at one of several possible positions, and the color of which can briefly change. Participants are explicitly instructed to detect the changes in dot color. However, unbeknownst to them, the succession of dot positions follows a second-order eight-element sequence that is repeated during several practice blocks. A different but structurally equivalent second-order sequence is presented once at the end of training and during testing to allow for a direct measure of sequence learning. During both training and testing, performance is measured by the latencies of eye movements, defined as the time interval between the change in dot position and the first saccade initiated in the direction of the target. These latencies reflect the development of an implicit sequential knowledge, as they become progressively shorter with repetition of the learned sequence, and slow down when the untrained sequence is presented.

alternative possibility, the 'double-step' hypothesis, assumes that the succession of NREMS and REMS was required for optimal memory consolidation [46], whatever the memory system considered. Some evidence has supported this hypothesis in animal experiments [47-51]. In humans, the evidence remains scarce. Motor sequence learning is improved to a larger extent by a complete night of sleep including abundant amounts of both NREMS and REMS, compared with late night sleep alone [34]. Likewise, the positive effect of sleep on visual perceptual learning is larger if it includes both NREMS and REMS [44,45].

Sleep is also believed to facilitate fluid thinking and problem solving. Historically, anecdotal evidence exists for the positive influence of sleep on scientific and artistic creativity [52]. Recently, experimental evidence confirmed that sleep not only enhances the verbatim retention of learned material, but can also lead to behavioral modifications during sleep that entail the generation of novel representations based on information extracted from learned exemplars [53-54]. Similarly, sleep has been involved in selectively enhancing false memories (relative to accurate memories) [55]. However, this effect is still controversial. Another study did not report any beneficial effect of sleep while sleep deprivation enhanced false memories at retrieval [56].
Despite all of this evidence, a critical review of the effects of sleep suggests that the behavioral effects of sleep on memory are smaller than usually believed. In the declarative domain, the difference in recall rates between sleep and waking conditions, although significant, usually only amounts to a marginal fraction of the learned material (e.g., [41]). This suggests that most of the learned material can still be retained and consolidated during wakefulness, without the necessary intervention of sleep (refer to the latter section of this article). However, one could argue that the major behavioral effect of sleep on memory consolidation is revealed under conditions of interference. Indeed, sleep provides active protection against potential interferences resulting from encoding novel information on the day following the initial learning [57].

In the procedural domain, the effects of sleep on memory consolidation were also not as simple as originally thought. Significant gains in performance in motor sequence learning have not been reported exclusively after sleep and can occur over a waking period, depending on various experimental factors: post-training interval [33,58-59], circadian rhythms [60] or subject's awareness of the sequential material [23,34,58] (TABLE 1). In addition, gains in performance recorded with the FTT are, in fact, overestimated, if the fatigue accrued during initial training is not accounted 
Table 1. Examples of factors modulating memory consolidation characteristics.

\section{Type of} learning material

Declarative/procedural Recall/recognition

Emotional /neutral

New/old

Difficult/easy

\section{Type of retrieval test Type of learning}

Explicit/implicit

Fast/slow

Motivational factors

Attention/alertness/vigilance
Type of population Type of sleep surrounding learning

Genetics

Gender

Age

Environment

Health
Delay, duration before/after learning

Circadian

Homeostatic

Non-rapid eye

movement sleep

Rapid eye movement sleep for [61]. Finally, it should be stressed that a beneficial effect of sleep over wakefulness in the retention of recently learned material has not been reported for all experimental tasks. For example, auditory perceptual learning does not seem to be selectively enhanced by sleep [62]

To tone down these reservations, it is also possible that behavioral measures are insensitive to sleep-related modifications in memory. In other words, the absence of a behavioral effect of sleep on memory does not necessarily entail an absence of any effect. Owing to redundancy in brain circuitry, similar performance levels can be achieved by recruiting different functional networks. For instance, the ability to navigate a virtual maze learned 3 days earlier is equivalent in volunteers who were either sleep deprived (SD) or allowed to sleep on the first postencoding night (Figures 3 \& 4) [25]. However, during navigation, striatal activity is larger at retrieval in the sleep group than in SD subjects. These data suggest that brain activity is restructured during sleep in such a way that navigation in the virtual environment, initially related to a hippocampus-dependent spatial strategy, becomes progressively automatized and mediated by the striatum. Likewise, the recollection of emotional items $72 \mathrm{~h}$ after encoding does not differ between sleeping or SD subjects during the postencoding night [63]. However, larger responses were observed in the medial prefrontal cortex and the hippocampus in the sleep group. By contrast, after SD, subsequent recollection of negative items is related to responses in an amygdalo-occipital network. Again, this alternate network suggests that recollection of emotional stimuli relies on redundant neural systems.

In summary, there is currently a wealth of evidence indicating that sleep enhances the retention of newly learned material. Quantitatively, the positive influence of sleep on memory consolidation appears smaller that initially estimated. However, behavioral measures might be less sensitive than direct measures of brain activity during sleep in the assessment of sleep contribution to memory consolidation. In this respect, measures of the electromagnetic or hemodynamic activity of the brain appear a necessary step in the evaluation of the influence of sleep on memory processes.

Behavioral studies have also suggested that the effects of sleep on memory consolidation could not be easily framed merely in terms of sleep states, suggesting that neural events associated with specific sleep microstructure might be more relevant for offline processing of recent memories. Accordingly, recent research that aimed to characterize the mnemonic processes associated with slow oscillations, $\Delta$ waves, spindles, phasic REMS and sleep neuromodulatory context. Recently, the emphasis was put on the impact of NREMS oscillations on memory processes. Two distinct, equally inspiring and not necessarily exclusive hypotheses came under intense experimental scrutiny: the homeostatic synaptic downscaling and the systems-level consolidation in hippocampo-neocortical circuits. They are reviewed in the following sections.

\section{Hypothesis of a homeostatic synaptic downscaling during NREM sleep}

This hypothesis claims that wakefulness is associated with a net increase in synaptic strength in the brain, which would become energetically unsustainable in the long term [64-65]. During deep NREMS a slow $(<1 \mathrm{~Hz})$ oscillation emerges from cortical or thalamo-cortical populations. Unit recordings have demonstrated that neuronal activity during slow wave sleep (SWS) is characterized by a fundamental oscillation of membrane potential. This slow oscillation is recorded in all major types of neocortical neurons during NREMS and consists of a depolarizing phase, associated with important neuronal firing (the 'up state'), followed by a hyperpolarizing phase during which cortical neurons remain silent for a few hundred milliseconds (the 'down state') [66-67]. The slow oscillation occurs synchronously in large neuronal populations, the 
activity of which alternates between so-called $\mathrm{ON}$ and OFF states [65], in such a way that it is reflected on EEG recordings as large amplitude low frequency waves [68]. $\Delta$ waves $(1-4 \mathrm{~Hz})$ are faster waves of smaller amplitude that arise when the synchronization in the network is less marked $[65,69]$. Slow wave activity (SWA), in other words, the EEG power between 0.75 and $4 \mathrm{~Hz}$, is a compound parameter that quantifies the homeostatic sleep pressure accrued during wakefulness [70].

During NREM sleep, the hypothesis assumes that the slow oscillation would be associated with a downscaling of synaptic strength to a baseline

A

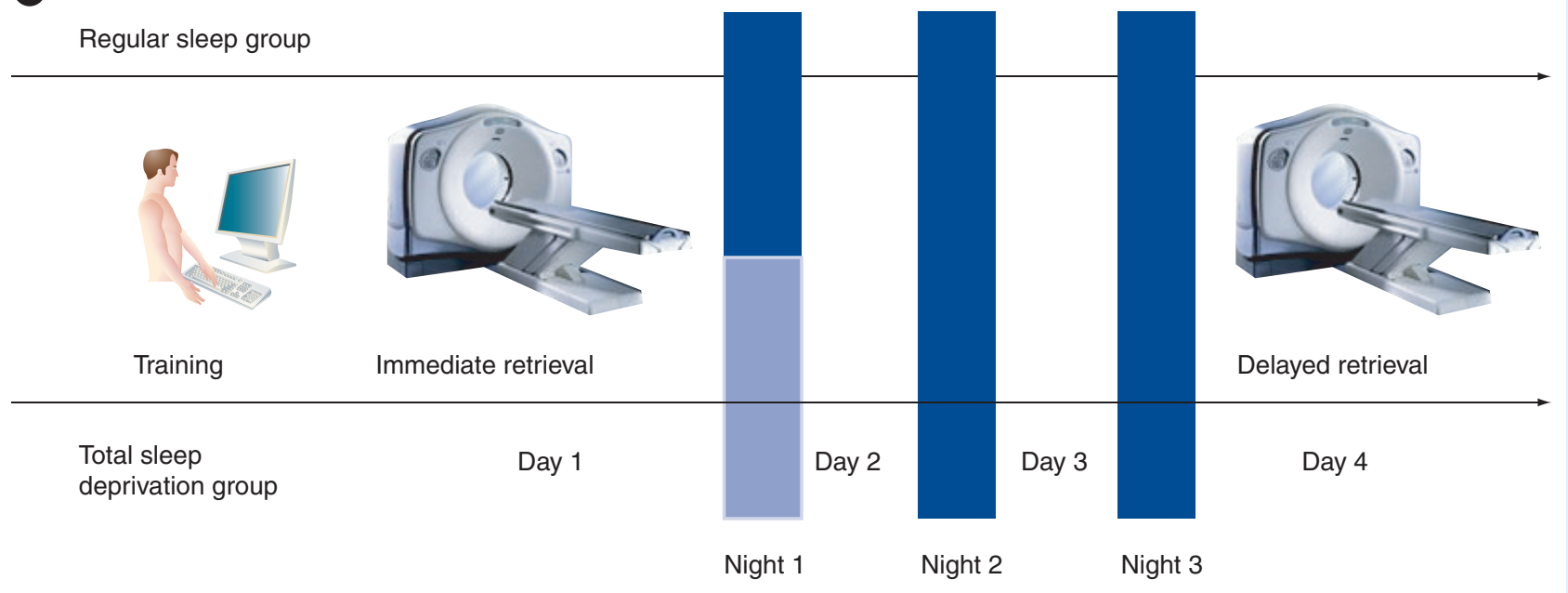

B
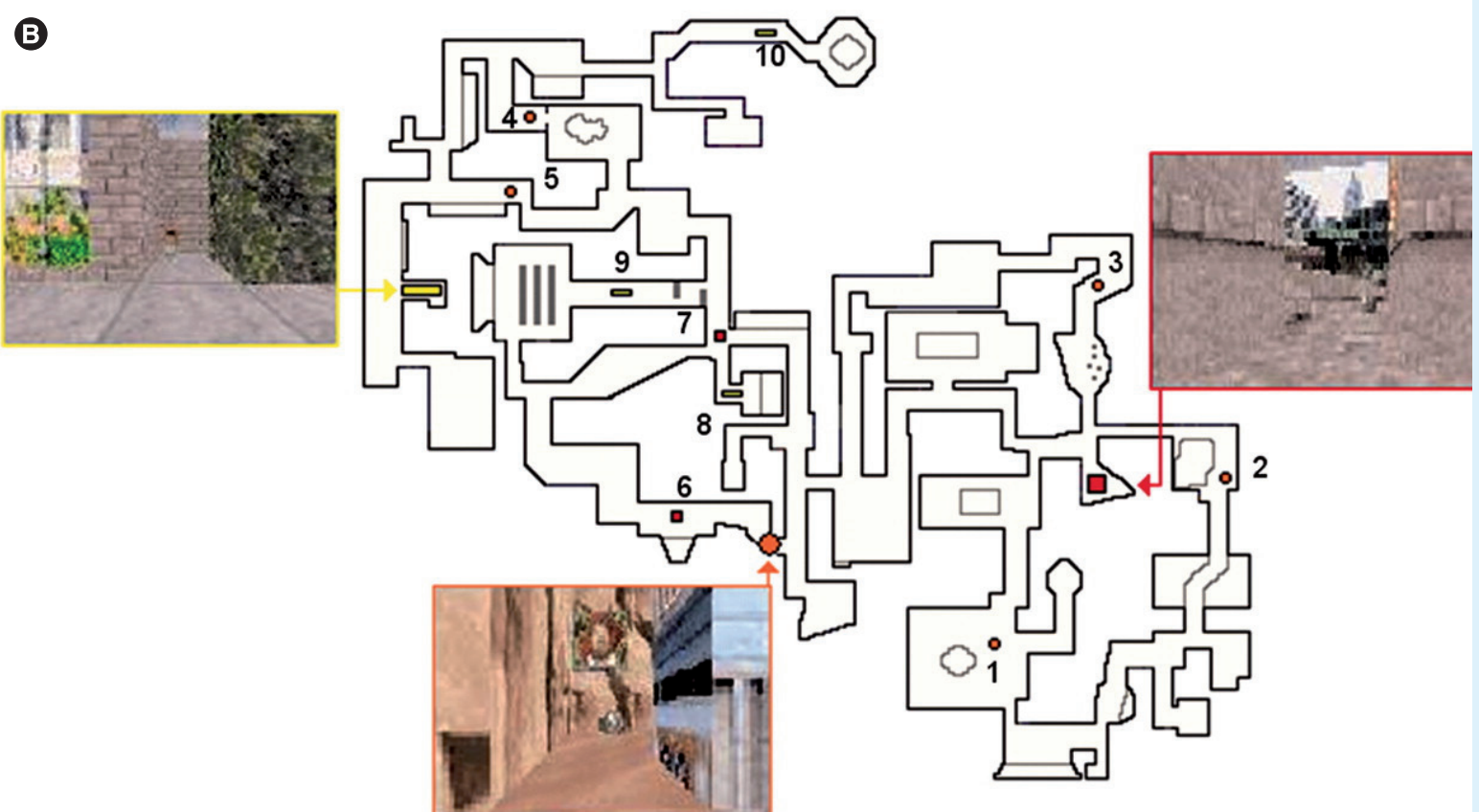

Figure 3. Experimental protocol and memory task. (A) Experimental design. After training on a desktop computer and subsequent testing in the scanner on day 1 (immediate retrieval), subjects were either totally sleep deprived or allowed regular sleep on the first post-training night. They were all retested under identical conditions during a second functional MRI session on day 4 (delayed retrieval). (B) The map depicts an aerial view of the color 3D virtual town in which subjects navigated at the ground level. Snapshots show the three locations used as targets for testing during the fMRI sessions. The ten starting points are represented by numbers, with associated symbols indicating the target location to reach.

Reproduced with permission from [25]. 
(A)
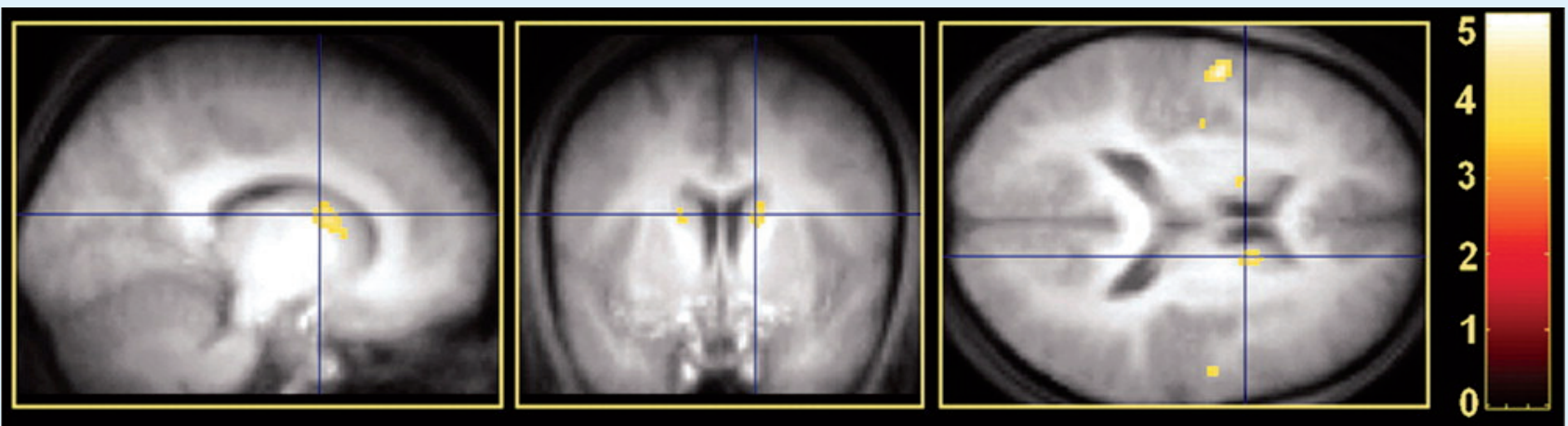

B
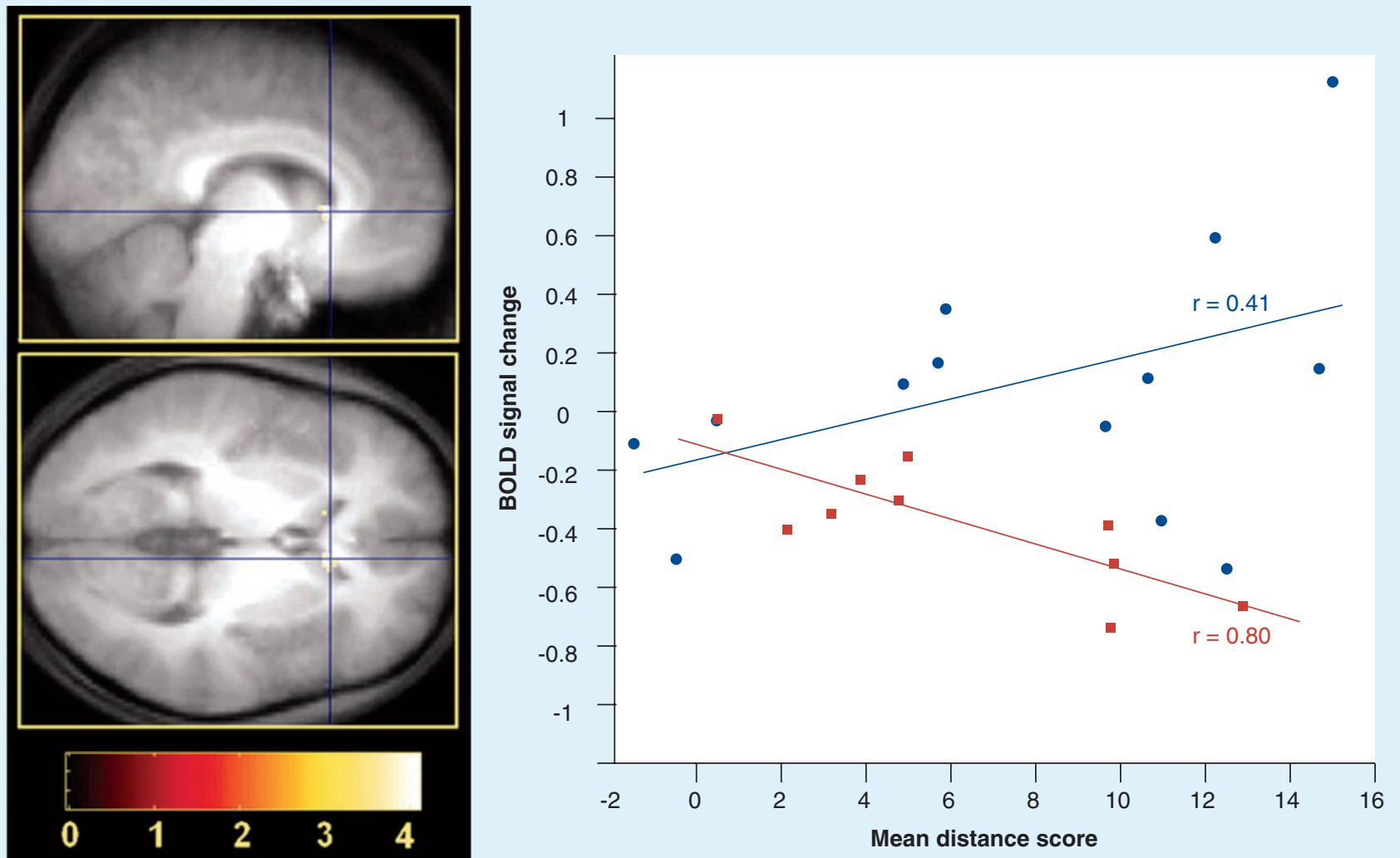

C
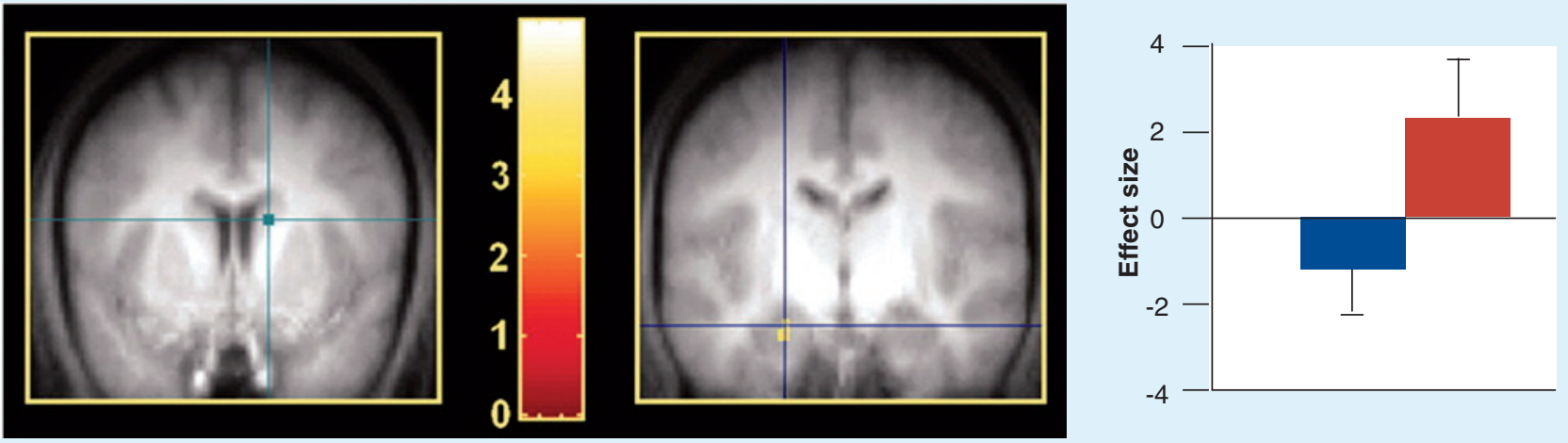

Figure 4. Sleep-dependent modulation of brain activity. Contrasts are displayed at $p<0.001$ (uncorrected) superimposed on the average T1-weighted MRI scan. Color bars code the value of the t-statistic associated with each voxel. (A) Higher activity elicited by place finding for the regular sleep (RS) compared with the totally sleep-deprived (TSD) group at delayed retrieval bilaterally in the caudate nucleus. Blue crosshair, right caudate nucleus $(14,8$ and $18 \mathrm{~mm} ; Z=3.73)$. (B) Between-group regression analyses of the average session performance on cerebral activity at delayed retrieval (sagittal and coronal sections). Blue crosshair, right caudate nucleus ( 8,22 and $4 \mathrm{~mm}$; $Z$ = 3.45). Scatter plot shows that brain response was correlated positively with performance in the RS group (blue; $r=0.41)$ but negatively in the TSD group (red; $r=-0.80$ ). (C) Psychophysiological interaction analysis using the right caudate nucleus (14, 8 and $18 \mathrm{~mm} ;$ green crosshair) as seed area. Coupling of activity between the caudate nucleus and the left hippocampus (coronal section) was negative in the RS group (blue), but positive in the TSD group (red). Blue crosshair, left hippocampus (22, 12 and $22 \mathrm{~mm} ; Z=3.15)$. Blue and red plots show the size of effect for each group. Error bars are standard deviations. Reproduced with permission from [25]. 
level, a process that is beneficial for learning and memory. The synaptic downscaling would be a general phenomenon occurring throughout the brain, one that is modulated locally by the amount of neural activity and synaptic strength enhancement accumulated during the day.

In support of this hypothesis, an increase in SWA is selectively observed after training to a visuo-motor adaptation task, over scalp areas that are deemed critical in this type of learning [43]. By contrast, arm immobilization results for a decrease in SWA over controlateral sensorimotor areas during subsequent NREMS [71]. Local increases in SWA were also reported when cortical activity was experimentally induced by a vibratory stimulation of the hand [72], transcranial magnetic stimulation [73] or when spike timingdependent activity was elicited during waking by transcranial-paired-associative stimulation [74]. Moreover, after learning lists of word-pair associates, during the surface-positive half-waves of NREMS slow waves, coherence is enhanced over widespread scalp areas in the slow-oscillatory and $\Delta$ bands [75]. Similar increases in SWA were reported in rats exposed to an enriched environment and appear to be associated with the release of BDNF [76]. At the cellular level, the slope and amplitude of cortical evoked responses, taken as markers of local synaptic strength, increase after waking and decrease after sleep in proportion with changes in SWA [77]. At the cellular level, multiunit recordings showed that firing rates and synchrony decrease after sleep. Changes in firing patterns in NREMS correlate with changes in SWA [65].

At the molecular level, in rat cortex and hippocampus, GluR1-containing AMPA receptor (AMPAR) levels are high during wakefulness and low during sleep, and changes in the phosphorylation states of AMPARs, CamKII and GSK $3 \beta$ are consistent with synaptic potentiation during wakefulness and depression during sleep [77]. Similar findings were recently reported in the fly, which provides evidence for the generality of this phenomenon [78].

However, for the sake of completeness, it should be mentioned that not all forms of sleepdependent plasticity seem to follow this general scheme. During neurodevelopment in kittens, the plasticity induced by monocular deprivation can be inhibited by the administration during sleep of NMDA receptor (NMDAR) and cAMP-dependent protein kinase antagonists (PKA) [79]. These findings suggest a synaptic strengthening during sleep in contrast to the downscaling hypothesis.

\section{Sleep-dependent systems-level memory consolidation \& hippocampo-neocortical dialog}

The second hypothesis pertains primarily to hippocampus-dependent memories. The classical theory of memory consolidation claims that during consolidation, hippocampus-dependent memories become progressively independent of the limbic structures and are gradually stored in cortical circuits $[21,80]$. Sleep would participate in this systems-level memory consolidation by promoting the functional interplay between hippocampal neural ensembles and neocortical areas [81].

This hypothesis implies that new experiences modify the activity of hippocampo-neocortical circuits during subsequent NREMS. At the systems level, human brain activity during sleep, as assessed by PET, is indeed significantly modified by previous waking experience. After the exploration of a virtual 3D maze the activity is enhanced during NREMS in occipital, parietal and mesio-temporal areas [82]. Moreover, the increase in hippocampal activity is linearly related to the individual gain in the ability to navigate in the maze the next day, suggesting that the changes in hippocampal activity during NREMS relate to the offline processing of topographical memory.

By contrast, sleep deprivation should hinder the offline processing of memory traces during NREMS and alter the neural correlates of subsequent retrieval. Accordingly, functional neuroimaging studies showed that SD during the first post-training night invariably modifies responses subsequently associated with retrieval. For instance, recall of word-pair associates $48 \mathrm{~h}$ after encoding is associated with larger hippocampal responses in subjects allowed to sleep on the post-encoding night compared with SD subjects [41]. Modifications of brain responses during retrieval are also modified by post-training SD for other memory tasks: topographical memory (see above) [25], emotional memory (see above) [63] and motor sequence learning [33-34].

After SD during the first post-training night, changes in brain responses associated with memory retrieval continue to be observed several months after encoding (see Figures 5 \& 6) [41,63,83], suggesting that sleep immediately following encoding modulates the early consolidation and conditions the structure of long-term memory at the systems level.

At the cellular level, the slow rhythm organizes other NREMS oscillations in a coalescence of rhythms so that spindles and $\gamma$ oscillations 
A

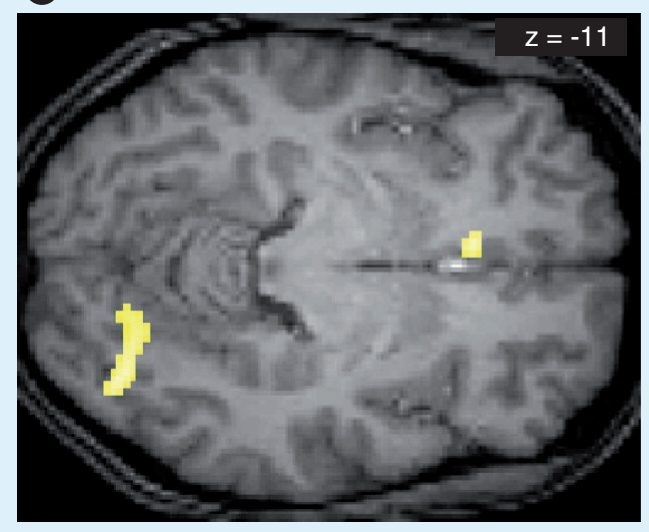

\section{B}

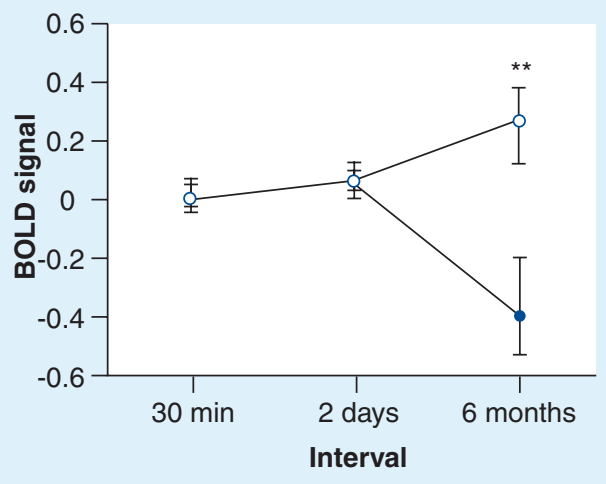

Figure 5. Differences in brain activity during a 6 -month retest session for correctly recalled words learned before sleep versus before sleep deprivation in a paired-associate word task. (A) Correct word recall after 6 months activates the medial-prefrontal cortex (mPFC) and the occipital cortex more strongly for words from the sleep condition than for words from the sleepdeprivation condition. Note that at the 2-day interval, no activity per se was found, but only a strong functional relation to hippocampal activity. At the 6-month interval, independent mPFC activity is found, but no more significant hippocampal activity. (B) The difference in brain activity in the MPFC developed mainly during the interval between the 2-day and 6 -month recall sessions. It is supported by a steady increase in MPFC activity for words from the sleep condition over the 6 -month period (open circles) and a marked drop in MPFC activity for words from the sleep-deprived condition (filled circle) during the 6 -month session $([-626-10], Z=-3.87, P$ SVC $=0.004)$.

Reproduced with permission from [83].

are more likely to occur during the up phase of the slow oscillation [84]. Likewise, hippocampal activity during NREMS is characterized by sharp waves and ripples, which are synchronous to the cortical slow oscillation [85-88], although it is not yet clear which oscillation is driving the other [86,89-91]. Finally, the slow oscillation organizes the neural firing of arousing structures such as the locus coeruleus (LC) [92]. Collectively, these data suggest that the up-state of the cortical slow oscillation constitutes a remarkable period during which the activity of various brain structures, in the cortex (slow waves and spindles), the hippocampus (sharp-wave ripples) and subcortical structures (striatum and LC) is synchronized, thereby fostering functional interactions associated with systems-level memory consolidation.

A key finding supporting this hypothesis is that sequences of neural discharges recorded in neural ensembles during wakefulness were spontaneously repeated during sleep, especially during hippocampal sharp waves and ripples, which are coherent with cortical slow oscillation, was observed in various brain structures such as the hippocampus, neocortical areas [87,93-95], the thalamus [96] or the striatum [97]. Importantly, reactivation of firing patterns in the neocortex is synchronized to hippocampal sharp waves [87,94], a condition favorable to cortico-hippocampal interactions. In addition, these reactivations appear to depend on learning as the replayed firing patterns appear only after the acquisition of new rules [94]. Simultaneous recordings in the hippocampus and prefrontal cortex in the rat demonstrated that cells in prefrontal cortex fire consistently within $100 \mathrm{~ms}$ after hippocampal cells during NREMS [88]. This result provides the first evidence at the single-cell-pair level for highly consistent directional interactions between these areas within the window of plasticity. Moreover, these interactions were driven by hippocampal sharp-wave/ripple bursts in SWS and are sharply reduced during REMS [88]. Collectively, these data support the hypothesis that during sleep, hippocampo-neocortical interactions may progressively transfer the burden of memory from hippocampal ensembles to long-term neocortical stores.

Sleep spindles are a hallmark of light NREMS (mostly stage 2 sleep) and, in humans, consist of waxing and waning $11-15 \mathrm{~Hz}$ oscillations, lasting $0.5-3 s[19]$. They are generated by the thalamus, which acts as a pacemaker [98-99], and result from reciprocal rhythmic interactions between reticular and thalamo-cortical cells. Postinhibitory rebound spike bursts in thalamo-cortical cells, induced by a recurrent inhibition by reticular cells, entrain cortical populations in spindle oscillations [100]. In turn, a cortico-thalamic feedback synchronizes spindle oscillations in widespread 
thalamic territories [101]. As spindles entrain synchronous firing in large thalamo-cortical neural populations, they are in a good position to allow for the modifications in the neural representations of recent memories. In support of this hypothesis, spindle activity increases after training on declarative [102-104] and procedural [105-107] memory tasks. Enhancing slow oscillations by direct current transcranial stimulation increases the power in the spindle frequency band and leads to a better retention of declarative memory the next morning [108]. At the cellular level, it was shown that repetitive spike bursts mimicking firing patterns observed during spontaneous spindles reliably induced short- and long-term potentiation in cortical neurons of rat brain slices [109]. It has also been suggested that activity in the spindle band would trigger molecular cascades involved in brain plasticity by increasing intracellular calcium levels [110].

Finally, the modifications in neuromodulation associated with sleep might provide a favorable context for memory offline processing. NREMS is associated with a decrease in cholinergic, adrenergic and serotonergic drive [111]. For example, acetylcholine inhibits feedback loops within the hippocampus and between the hippocampus and neocortex [112]. A low cholinergic activity during SWS would be required to promote the spontaneous replay of newly acquired information in the hippocampus. In line with this assumption, augmenting cholinergic tone during NREMS by infusion of physostigmine in humans causes deterioration in later performance on a declarative memory task [113].

\section{REMS \& pontine waves}

REMS represents a state of consciousness distinct from wakefulness and NREMS, characterized by persistent ('tonic') features such as relatively fast-frequency, low-amplitude oscillations on EEG recordings and muscular atonia, but also by phasic characteristics such as bursts of REMS, muscle twitches and swift modifications in autonomic functions [114]. The implication of REMS in memory processing is still a subject of debate [115] and at the very least appears dispensable in adult humans since REMS suppression by administration of selective serotonin or norepinephrine reuptake inhibitors has not demonstrated any detrimental effect on motor skill or word-pair learning [116].

On the other hand, there is also positive evidence for the implication of REMS in memory processing. At the systems level, training on a procedural task (a motor sequence learning task based on probabilistic serial reaction times, Box 1) results in increased activity in premotor and occipital cortices, thalamus and upper brainstem during subsequent REMS. In addition, the functional connectivity between the premotor cortex and posterior parietal cortex and presupplementary motor area is also enhanced during post-training REMS [117]. These changes in regional activity during REMS are observed only if the learned material is structured by hidden rules and not when the material is random, suggesting that they are related to the processing of the underlying higher-order structure [118].
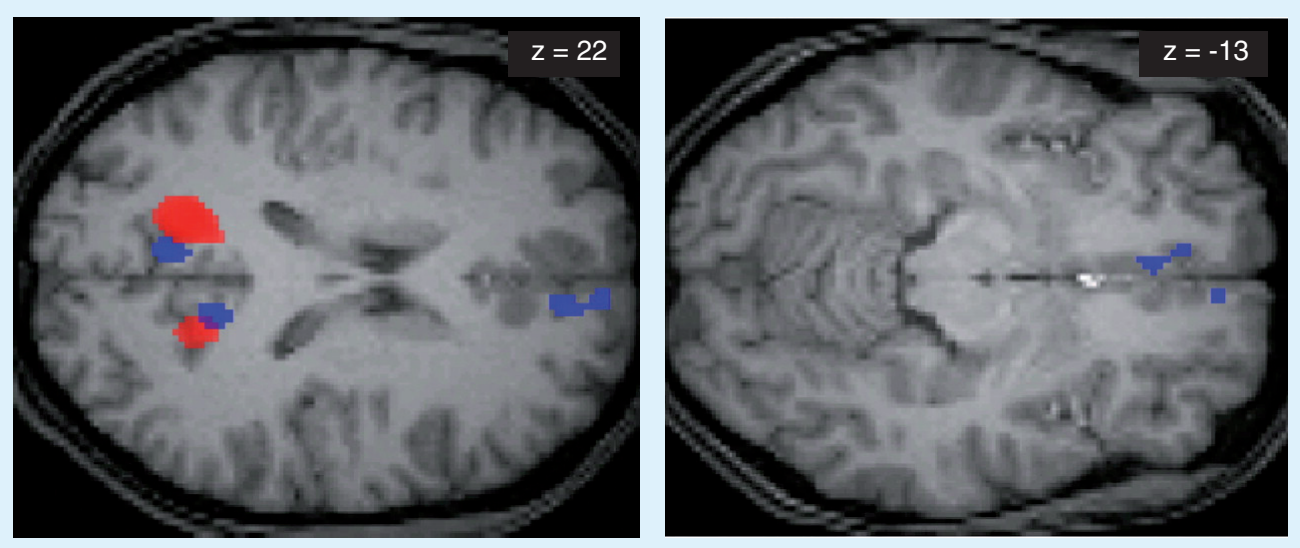

Figure 6. Obtained from the paired associate words task protocol, areas functionally related to the hippocampus during correct word recall on day $\mathbf{2}$ after sleep or sleep deprivation. At 2 days after learning, if subjects were allowed to sleep, the hippocampus was functionally connected to the precuneus and the medial-prefrontal cortex during correct word recall (blue). However, if subjects were sleep-deprived the night after learning, the prefrontal sites did not relate to hippocampal activation (red).

Reproduced with permission from [83]. 
Within REMS, it appears that phasic-REMSassociated neural activity is involved in memory consolidation. One of the main characteristics of REMS in animals consists of prominent phasic bioelectrical potentials that occur isolated or in bursts during the transition from SWS to REMS or during REMS itself (for a review see 119]). These waves can be observed from many parts of the animal brain [120], but are most easily recorded in the pons, the lateral geniculate bodies and the occipital cortex [121] and therefore are termed ponto-geniculo-occipital (PGO) waves in cats [122] or pontine waves in rats [122]. Typically, bursts of pontine waves are associated with REMS. Several observations suggest that PGO waves also occur during human sleep [123128]. In rats, the density of pontine waves during post-training REMS is proportional to the gain in performance to an avoidance task [129]. Suppressing pontine waves, even without modifying the amounts of REMS, annihilates learning. By contrast, the pharmacological induction of pontine waves (by microinfusion of carbachol) enhanced subsequent performance to the avoidance task. These effects appear to be related to the activation of glutamatergic neurotransmission, gene expression and protein synthesis in the hippocampus and the amygdala [130]. Accordingly, synaptic transmission and late-LTP in the rat hippocampus are positively correlated with REMS quantities [131]. Reversely, REMSdeprivation decreases synaptic transmission and long-term potentiation selectively in dorsal hippocampus. Intriguingly, levels in GluR1, NR1 and p-ERK1/2 decrease without changes in GluR1 and NR1 mRNA expression, suggesting sleep-induced modulation of translational, rather than transcriptional mechanisms [131].

\section{Wakefulness}

The data reviewed above does not mean that memory consolidation occurs exclusively during sleep. Indeed, experimental evidence exists for learningrelated changes in spontaneous brain activity during post-training wakefulness. Replays of neural firing sequences from a previous experience are recorded in the rat hippocampus during brief pauses in waking behavior, especially when the rat has recently been in motion [132]. Intriguingly, neural firing sequences can be replayed in a temporally reversed order during waking periods relative to previous spatial experience [133]. These reverse replays would have a critical role in support of learning in hippocampus-dependent tasks by propagating valuable information from the rewarded location backwards along incoming trajectories [133].

Likewise, in non-human primates, the correlation structure between somatosensory and parietal cortex induced by reaching and navigation tasks was maintained during post-training resting wakefulness [134]. In humans, the brain activity elicited during a new learning episode (navigation or motor sequence learning) modulates brain responses to an unrelated cognitive task (auditory oddball task), during the waking period following the end of training [135]. Collectively, these data indicate that memory is actively processed during post-training wakefulness.

\section{Executive summary}

\section{Behavioral effects}

- Functional neuroimaging techniques show that the distribution of regional brain activity during sleep is influenced by previous waking experience.

\section{The hypothesis of a homeostatic synaptic downscaling during NREM sleep}

- EEG and molecular data tend to support the hypothesis that NREM sleep, and more specifically slow-wave sleep, is the reflection of both a global and local synaptic downscaling correlated with the amount of synaptic strengthening that has previously taken place during wakefulness.

The sleep-dependent systems-level memory consolidation \& the hippocampo-neocortical dialogue

- Neuroimaging as well as neurophysiological data support the classical memory consolidation hypothesis stating that during sleep hippocampo-neocortical interactions may progressively transfer the burden of memory from hippocampal ensembles to long-term neocortical stores.

\section{REMS \& pontine waves}

- Often considered as dispensable, REMS is indeed implied in memory processing. Typical REMS phasic events such as the PGO waves are implied in learning, and there is good evidence that REMS promotes synaptic potentiation.

\section{Wakefulness}

- Experimental evidence exists for learning-related changes in spontaneous brain activity during post-training wakefulness, showing that memory is actively processed during wakefulness and not exclusively during sleep.

\section{Conclusion}

- Collectively, the available data indicate a positive influence of sleep onto memory consolidation. 


\section{Conclusions}

Memory consolidation is among the few brain functions that develop over time periods ranging from a few hours to (potentially) several months or years. It necessarily unfolds across states of wakefulness and sleep (and also various circadian phases). It is not surprising that these factors influence memory consolidation.
The respective role of neural mechanisms taking place during wakefulness and during sleep remains determined.

A comprehensive understanding of memory consolidation will eventually lead to its improved characterization at various levels of description, from the molecular to the behavioral level.

\section{Financial \& competing interests disclosure}

Personal research reported in this review was supported by the Belgian Fonds National de la Recherche Scientifique (FNRS), Fondation Médicale Reine Elisabeth (FMRE), Research Fund of the University of Liège and "Interuniversity Attraction Poles Programme - Belgian State Belgian Science Policy". Anahita Shaffii-Le Bourdiec, Laura Mascetti, Ariane Foret, Luca Matarazzo, Caroline Kussé and Pierre Maquet are supported by the FNRS. Vincenzo Muto is supported by the ULg. The authors have no other relevant affiliations or financial involvement with any organization or entity with a financial interest in or financial conflict with the subject matter or materials discussed in the manuscript apart from those disclosed.

No writing assistance was utilized in the production of this manuscript.

\section{Bibliography}

Papers of special note have been highlighted as:

- of interest

- of considerable interest

1. McGaugh JL: Memory - a century of consolidation. Science 287, 248-251 (2000).

2. Ebbinghaus H: Über das Gedächtnis, Untersuchungen zur Experimentellen Psychologie. Duncker und Humblot, Leipzig, Germany (1885).

3. Abel T, Lattal KM: Molecular mechanisms of memory acquisition, consolidation and retrieval. Curr. Opin Neurobiol. 11, 180-187 (2001).

4. Carew TJ, Sutton MA: Molecular stepping stones in memory consolidation. Nat. Neurosci. 4, 769-771 (2001).

-5. Izquierdo I, Bevilaqua LR, Rossato JI, Bonini JS, Medina JH, Cammarota M: Different molecular cascades in different sites of the brain control memory consolidation. Trends Neurosci. 29, 496-505 (2006).

6. Wang H, Hu Y, Tsien JZ: Molecular and systems mechanisms of memory consolidation and storage. Prog. Neurobiol. 79, 123-135 (2006).
Bailey CH, Kandel ER, Si K: The persistence of long-term memory: a molecular approach to self-sustaining changes in learning-induced synaptic growth. Neuron 44, 49-57 (2004).

Bahar A, Dorfman N, Dudai Y: Amygdalar circuits required for either consolidation or extinction of taste aversion memory are not required for reconsolidation. Eur. J. Neurosci. 19, 1115-1118 (2004).

Gould E, Beylin A, Tanapat P, Reeves A, Shors TJ: Learning enhances adult neurogenesis in the hippocampal formation. Nat. Neurosci. 2, 260-265 (1999).

10. Guzman-Marin R, Bashir T, Suntsova N, Szymusiak R, McGinty D: Hippocampal neurogenesis is reduced by sleep fragmentation in the adult rat. Neuroscience 148, 325-333 (2007).

11. Guzman-Marin R, Suntsova N, Bashir T, Nienhuis R, Szymusiak R, McGinty D: Rapid eye movement sleep deprivation contributes to reduction of neurogenesis in the hippocampal dentate gyrus of the adult rat. Sleep 31, 167-175 (2008).

12. Guzman-Marin R, Suntsova N, Methippara M, Greiffenstein R, Szymusiak R, McGinty D: Sleep deprivation suppresses neurogenesis in the adult hippocampus of rats. Eur. J. Neurosci. 22, 2111-2116 (2005).

13. Shors TJ, Miesegaes G, Beylin A, Zhao M, Rydel T, Gould E: Neurogenesis in the adult is involved in the formation of trace memories. Nature 410, 372-376 (2001).

14. Bliss TV, Collingridge GL: A synaptic model of memory: long-term potentiation in the hippocampus. Nature 361, 31-39 (1993).

- Long-term potentiation is shown to be a molecular correlate of memory consolidation.

15. Benington JH, Frank MG: Cellular and molecular connections between sleep and synaptic plasticity. Prog. Neurobiol. 69, 71-101 (2003).

16. Bergmann TO, Molle M, Marshall L, Kaya-Yildiz L, Born J, Siebner RH: A local signature of LTP- and LTD-like plasticity in human NREM sleep. Eur. J. Neurosci. 27, 2241-2249 (2008).
17. McDermott CM, LaHoste GJ, Chen C, Musto A, Bazan NG, Magee JC: Sleep deprivation causes behavioral, synaptic, and membrane excitability alterations in hippocampal neurons. J. Neurosci. 23, 9687-9695 (2003).

18. Tadavarty R, Kaan TK, Sastry BR: Long-term depression of excitatory synaptic transmission in rat hippocampal CA1 neurons following sleep-deprivation. Exp. Neurol. 216, 239-242 (2009).

19. Werk CM, Klein HS, Nesbitt CE, Chapman CA: Long-term depression in the sensorimotor cortex induced by repeated delivery of $10 \mathrm{~Hz}$ trains in vivo. Neuroscience 140, 13-20 (2006).

20. Doyon J, Benali H: Reorganization and plasticity in the adult brain during learning of motor skills. Curr. Opin Neurobiol. 15, 161-167 (2005).

21. Frankland PW, Bontempi B: The organization of recent and remote memories. Nat. Rev. Neurosci. 6, 119-130 (2005).

22. Maquet P: The role of sleep in learning and memory. Science 294, 1048-1052 (2001).

- Sleep reactivations of neuronal firing patterns triggered by new experiences during previous wakefulness may be linked to memory consolidation.

23. Robertson EM, Pascual-Leone A, Press DZ: Awareness modifies the skill-learning benefits of sleep. Curr. Biol. 14, 208-212 (2004).

24. Atienza M, Cantero JL, Stickgold R: Posttraining sleep enhances automaticity in perceptual discrimination. J. Cogn. Neurosci. 16, 53-64 (2004).

25. Orban P, Rauchs G, Balteau E et al.: Sleep after spatial learning promotes covert reorganization of brain activity. Proc. Natl Acad. Sci. USA 103, 7124-7129 (2006).

26. Korman M, Raz N, Flash T, Karni A: Multiple shifts in the representation of a motor sequence during the acquisition of skilled performance. Proc. Natl Acad. Sci. USA 100, 12492-12497 (2003).

27. Rasch B, Born J: Maintaining memories by reactivation. Curr. Opin Neurobiol. 17, 698-703 (2007). 
28. Stickgold R, Walker MP: Sleep and memory: the ongoing debate. Sleep 28, 1225-1227 (2005).

29. Ellenbogen JM, Payne JD, Stickgold R: The role of sleep in declarative memory consolidation: passive, permissive, active or none? Curr. Opin Neurobiol. 16, 716-722 (2006).

30. Walker MP, Stickgold R: Sleep, memory, and plasticity. Annu. Rev. Psychol. 57, 139-166 (2006).

31. Born J, Rasch B, Gais S: Sleep to remember. Neuroscientist 12, 410-424 (2006).

32. Walker MP, Brakefield T, Hobson JA, Stickgold R: Dissociable stages of human memory consolidation and reconsolidation. Nature 425, 616-620 (2003).

-33. Walker MP, Brakefield T, Morgan A, Hobson JA, Stickgold R: Practice with sleep makes perfect: sleep-dependent motor skill learning. Neuron 35, 205-211 (2002).

34. Fischer S, Hallschmid M, Elsner AL, Born J: Sleep forms memory for finger skills. Proc. Natl Acad. Sci. USA 99, 11987-11991 (2002).

35. Plihal W, Born J: Effects of early and late nocturnal sleep on priming and spatial memory. Psychophysiology 36, 571-582 (1999).

36. Karni A, Tanne D, Rubenstein BS, Askenasy JJ, Sagi D: Dependence on REM sleep of overnight improvement of a perceptual skill. Science 265, 679-682 (1994).

37. Fowler MJ, Sullivan MJ, Ekstrand BR: Sleep and memory. Science 179, 302-304 (1973).

38. Tilley AJ, Empson JA: REM sleep and memory consolidation. Biol. Psychol. 6, 293-300 (1978).

39. Barrett TR, Ekstrand BR: Effect of sleep on memory: III. Controlling for time-of-day effects. J. Exp. Psychol. 96, 321-327 (1972).

40. Yaroush R, Sullivan MJ, Ekstrand BR: Effect of sleep on memory: II. Differential effect of the first and second half of the night. J. Exp. Psychol. 88, 361-366 (1971).

41. Gais S, Lucas B, Born J: Sleep after learning aids memory recall. Learn Mem. 13, 259-262 (2006).

42. Rasch B, Buchel C, Gais S, Born J: Odor cues during slow-wave sleep prompt declarative memory consolidation. Science 315, 1426-1429 (2007).

43. Huber R, Ghilardi MF, Massimini M, Tononi G: Local sleep and learning. Nature 430, 78-81 (2004).

- The downscaling events taking place during sleep may be locally regulated. Hence, sleep may be a local phenomenon rather than a simple behavioral state.
44. Mednick S, Nakayama K, Stickgold R: Sleep-dependent learning: a nap is as good as a night. Nat. Neurosci. 6, 697-698 (2003).

45. Gais S, Plihal W, Wagner U, Born J: Early sleep triggers memory for early visual discrimination skills. Nat. Neurosci. 3 , 1335-1339 (2000).

46. Giuditta A: A sequential hypothesis for the function of sleep. Sleep 222-224 (1984).

47. Ambrosini MV, Langella M, Carnevale GUA, Giuditta A: The sequential hypothesis of sleep function. III. The structure of postacquisition sleep in learning and nonlearning rats. Physiol. Behav. 51, 217-226 (1992).

48. Ambrosini MV, Mariucci G, Bruschelli G, Colarieti L, Giuditta A: Sequential hypothesis of sleep function. V. Lengthening of post-trial SS episodes in reminiscent rats. Physiol. Behav. 58, 1043-1049 (1995).

49. Ambrosini MV, Mariucci G, Colarieti L, Bruschelli G, Carobi C, Giuditta A: The structure of sleep is related to the learning ability of rats. Eur. J. Neurosci. 5, 269-275 (1993).

50. Ambrosini MV, Sadile AG, Gironi Carnevale UA, Mattiaccio A, Giuditta A: The sequential hypothesis on sleep function. II. A correlative study between sleep variables and newly synthesized brain DNA. Physiol. Behav. 43, 339-350 (1988).

51. Ambrosini MV, Sadile AG, Gironi Carnevale UA, Mattiaccio M, Giuditta A: The sequential hypothesis on sleep function. I. Evidence that the structure of sleep depends on the nature of the previous waking experience. Physiol. Behav. 43, 325-337 (1988).

52. Maquet P, Ruby P: Psychology: insight and the sleep committee. Nature 427, 304-305 (2004).

-53. Ellenbogen JM, Hu PT, Payne JD, Titone D, Walker MP: Human relational memory requires time and sleep. Proc. Natl Acad. Sci. USA 104, 7723-7728 (2007).

-54. Wagner U, Gais S, Haider H, Verleger R, Born J: Sleep inspires insight. Nature 427, 352-355 (2004).

-55. Payne JD, Schacter DL, Propper RE et al.: The role of sleep in false memory formation. Neurobiol. Learn Mem. 92, 327-334 (2009).

56. Diekelmann S, Landolt HP, Lahl O, Born J, Wagner U: Sleep loss produces false memories. PLoS One 3, E3512 (2008).

57. Ellenbogen JM, Hulbert JC, Jiang Y, Stickgold R: The sleeping brain's influence on verbal memory: boosting resistance to interference. PLoS One 4, E4117 (2009).

58. Press DZ, Casement MD, Pascual-Leone A, Robertson EM: The time course of off-line motor sequence learning. Brain Res. Cogn. Brain Res. 25, 375-378 (2005).
59. Hauptmann B, Karni A: From primed to learn: the saturation of repetition priming and the induction of long-term memory. Brain Res. Cogn. Brain Res. 13, 313-322 (2002).

60. Cajochen C, Knoblauch V, Wirz-Justice A, Krauchi K, Graw P, Wallach D: Circadian modulation of sequence learning under high and low sleep pressure conditions. Behav. Brain Res. 151, 167-176 (2004).

61. Rickard TC, Cai DJ, Rieth CA: Sleep does not enhance motor sequence learning. J. Exp. Psychol. Learn Mem. Cogn. 34, 834-842 (2008).

62. Gottselig JM, Hofer-Tinguely G, Borbely AA et al:: Sleep and rest facilitate auditory learning. Neuroscience 127, 557-561 (2004).

63. Sterpenich V, Albouy G, Boly M et al.: Sleep-related hippocampo-cortical interplay during emotional memory recollection. PLoS Biol. 5, E282 (2007).

64. Tononi G, Cirelli C: Sleep function and synaptic homeostasis. Sleep Med. Rev. 10, 49-62 (2006).

- A new and promising approach to unravel the function of sleep - sleep as a homeostatic process designed to downscale the neuronal assemblies potentiated during a previous waking period.

65. Vyazovskiy VV, Olcese U, Lazimy YM et al.: Cortical firing and sleep homeostasis. Neuron 63, 865-878 (2009).

66. Steriade M, Nunez A, Amzica F: Intracellular analysis of relations between the slow $(<1 \mathrm{~Hz})$ neocortical oscillation and other sleep rhythms of the electroencephalogram. J. Neurosci. 13, 3266-3283 (1993).

67. Steriade M, Timofeev I, Grenier F: Natural waking and sleep states: a view from inside neocortical neurons. J. Neurophysiol. 85, 1969-1985 (2001).

68. Steriade M, Nunez A, Amzica F: A novel slow $(<1 \mathrm{~Hz})$ oscillation of neocortical neurons in vivo: depolarizing and hyperpolarizing components. J. Neurosci. 13, 3252-3265 (1993).

69. Esser SK, Hill SL, Tononi G: Sleep homeostasis and cortical synchronization: I. Modeling the effects of synaptic strength on sleep slow waves. Sleep 30, 1617-1630 (2007).

70. Achermann P, Borbely AA: Mathematical models of sleep regulation. Front Biosci. 8, S683-S693 (2003).

71. Huber R, Ghilardi MF, Massimini M et al.: Arm immobilization causes cortical plastic changes and locally decreases sleep slow wave activity. Nat. Neurosci. 9, 1169-1176 (2006).

72. Kattler H, Dijk DJ, Borbely AA: Effect of unilateral somatosensory stimulation prior to sleep on the sleep EEG in humans. J. Sleep Res. 3, 159-164 (1994). 
73. Huber R, Esser SK, Ferrarelli F, Massimini M, Peterson MJ, Tononi G: TMS-induced cortical potentiation during wakefulness locally increases slow wave activity during sleep. PLoS One 2, E276 (2007).

74. Huber R, Maatta S, Esser SK et al.: Measures of cortical plasticity after transcranial paired associative stimulation predict changes in electroencephalogram slow-wave activity during subsequent sleep. J. Neurosci. 28, 7911-7918 (2008).

75. Molle M, Marshall L, Gais S, Born J: Learning increases human electroencephalographic coherence during subsequent slow sleep oscillations. Proc. Natl Acad. Sci. USA 101, 13963-13968 (2004).

76. Huber R, Tononi G, Cirelli C: Exploratory behavior, cortical BDNF expression, and sleep homeostasis. Sleep 30, 129-139 (2007).

77. Vyazovskiy VV, Cirelli C, Pfister-Genskow M, Faraguna U, Tononi G: Molecular and electrophysiological evidence for net synaptic potentiation in wake and depression in sleep. Nat. Neurosci. 11, 200-208 (2008).

78. Gilestro GF, Tononi G, Cirelli C: Widespread changes in synaptic markers as a function of sleep and wakefulness in Drosophila. Science 324, 109-112 (2009).

79. Aton SJ, Seibt J, Dumoulin MC, Coleman T, Shiraishi M, Frank MG: The sedating antidepressant trazodone impairs sleepdependent cortical plasticity. PLoS One 4, E6078 (2009).

80. Alvarez P, Squire LR: Memory consolidation and the medial temporal lobe: a simple network model. Proc. Natl Acad. Sci. USA 91, 7041-7045 (1994).

81. Buzsaki G: Hippocampal sharp waves: their origin and significance. Brain Res. 398, 242-252 (1986).

82. Peigneux P, Laureys S, Fuchs S et al:: Are spatial memories strengthened in the human hippocampus during slow wave sleep? Neuron 44, 535-545 (2004).

83. Gais S, Albouy G, Boly M et al.: Sleep transforms the cerebral trace of declarative memories. Proc. Natl Acad. Sci. USA 104, 18778-18783 (2007).

84. Steriade M, Amzica F: Coalescence of sleep rhythms and their chronology in corticothalamic networks. Sleep Res. Online 1, 1-10 (1998).

85. Clemens Z, Molle M, Eross L, Barsi P, Halasz P, Born J: Temporal coupling of parahippocampal ripples, sleep spindles and slow oscillations in humans. Brain 130, 2868-2878 (2007).
86. Isomura Y, Sirota A, Ozen S et al.: Integration and segregation of activity in entorhinalhippocampal subregions by neocortical slow oscillations. Neuron 52, 871-882 (2006).

87. Ji D, Wilson MA: Coordinated memory replay in the visual cortex and hippocampus during sleep. Nat. Neurosci. 10, 100-107 (2007).

88. Wierzynski CM, Lubenov EV, Gu M, Siapas AG: State-dependent spike-timing relationships between hippocampal and prefrontal circuits during sleep. Neuron 61, 587-596 (2009).

89. Tononi G, Massimini M, Riedner BA: Sleepy dialogues between cortex and hippocampus: who talks to whom? Neuron 52, 748-749 (2006).

90. Molle M, Born J: Hippocampus whispering in deep sleep to prefrontal cortex - for good memories? Neuron 61, 496-498 (2009).

91. Diekelmann S, Wilhelm I, Born J: The whats and whens of sleep-dependent memory consolidation. Sleep Med. Rev. 13, 309-321 (2009).

92. Eschenko O, Sara SJ: Learning-dependent, transient increase of activity in noradrenergic neurons of locus coeruleus during slow wave sleep in the rat: brain stem-cortex interplay for memory consolidation? Cereb Cortex 18, 2596-2603 (2008).

-93. Euston DR, Tatsuno M, McNaughton BL: Fast-forward playback of recent memory sequences in prefrontal cortex during sleep. Science 318, 1147-1150 (2007).

94. Peyrache A, Khamassi M, Benchenane K, Wiener SI, Battaglia FP: Replay of rulelearning related neural patterns in the prefrontal cortex during sleep. Nat. Neurosci. 12, 919-926 (2009).

-95. Qin YL, McNaughton BL, Skaggs WE, Barnes CA: Memory reprocessing in corticocortical and hippocampocortical neuronal ensembles. Philos. Trans. R Soc. Lond. B Biol. Sci. 352, 1525-1533 (1997).

96. Ribeiro S, Gervasoni D, Soares ES et al.: Long-lasting novelty-induced neuronal reverberation during slow-wave sleep in multiple forebrain areas. PLoS Biol. 2, E24 (2004).

97. Pennartz CM, Lee E, Verheul J, Lipa P, Barnes CA, McNaughton BL: The ventral striatum in off-line processing: ensemble reactivation during sleep and modulation by hippocampal ripples. J. Neurosci. 24, 6446-6456 (2004).

98. Steriade M: Thalamic origin of sleep spindles: Morison and Bassett (1945). J. Neurophysiol. 73, 921-922 (1995).

99. Steriade M: The deafferented reticular thalamic nucleus generates spindle rhythmicity. J. Neurophysiol. 57(1), 260-273 (1987).
100. Steriade M, Jones E, Llinas R: Thalamic Oscillations and Signaling. Wiley-InterScience NY, USA (1990).

101. Contreras D, Steriade M: Spindle oscillation in cats: the role of corticothalamic feedback in a thalamically generated rhythm. J. Physiol. 490 (Pt 1), 159-179 (1996).

102. Gais S, Molle M, Helms K, Born J: Learning-dependent increases in sleep spindle density. J. Neurosci. 22, 6830-6834 (2002).

- Sleep spindles as an EEG correlate of learning efficacy.

103. Schabus M, Gruber G, Parapatics S et al.: Sleep spindles and their significance for declarative memory consolidation. Sleep 27 , 1479-1485 (2004).

104. Schmidt C, Peigneux P, Muto V et al: Encoding difficulty promotes postlearning changes in sleep spindle activity during napping. J. Neurosci. 26, 8976-8982 (2006).

105. Fogel SM, Smith CT: Learning-dependent changes in sleep spindles and Stage 2 sleep. J. Sleep Res. 15, 250-255 (2006).

106. Fogel SM, Smith CT, Cote KA: Dissociable learning-dependent changes in REM and non-REM sleep in declarative and procedural memory systems. Behav. Brain Res.. 180, 48-61 (2007).

107. Morin A, Doyon J, Dostie V et al: : Motor sequence learning increases sleep spindles and fast frequencies in post-training sleep. Sleep 31, 1149-1156 (2008).

108. Marshall L, Helgadottir H, Molle M, Born J: Boosting slow oscillations during sleep potentiates memory. Nature 444, 610-613 (2006).

109. Rosanova M, Ulrich D: Pattern-specific associative long-term potentiation induced by a sleep spindle-related spike train. J. Neurosci. 25, 9398-9405 (2005).

110. Sejnowski TJ, Destexhe A: Why do we sleep? Brain Res. 886, 208-223 (2000).

111. Hobson JA: Current concepts. Sleep: biochemical aspects. N. Engl. J. Med. 281, 1468-1470 (1969).

112. Hasselmo ME: Neuromodulation: acetylcholine and memory consolidation. Trends Cogn. Sci. 3, 351-359 (1999).

113. Gais S, Born J: Low acetylcholine during slow-wave sleep is critical for declarative memory consolidation. Proc. Natl Acad. Sci. USA 101, 2140-2144 (2004).

114. Rechtschaffen A, Kales A (Eds). A Manual of Standardized Terminology, Techniques and Scoring System for Sleep Stages of Human Subjects. B.I.S.B.R. Institute. University of California, LA, USA, 1968.

- The bible of sleep EEG scoring methodology and patterns recognition. 
115. Siegel JM: The REM sleep-memory consolidation hypothesis. Science 294 , 1058-1063 (2001).

116. Rasch B, Pommer J, Diekelmann S, Born J: Pharmacological REM sleep suppression paradoxically improves rather than impairs skill memory. Nat. Neurosci. 12, 396-397 (2009).

117. Laureys S, Peigneux P, Phillips C et al: Experience-dependent changes in cerebral functional connectivity during human rapid eye movement sleep. Neuroscience 105 , 521-525 (2001).

118. Peigneux P, Laureys S, Fuchs S et al.: Learned material content and acquisition level modulate cerebral reactivation during posttraining rapid-eye-movements sleep. Neuroimage 20, 125-134 (2003).

119. Callaway CW, Lydic R, Baghdoyan HA, Hobson JA: Pontogeniculooccipital waves: spontaneous visual system activity during rapid eye movement sleep. Cell Mol. Neurobiol. 7, 105-149 (1987).

120. Hobson JA: The phasic electrical activity of the cortex and thalamus during desychonized sleep in cats. CR Seances Soc. Biol. Fil. 158, 2131-2135 (1964).

121. Mouret J, Jeannerod M, Jouvet M: Electrical activity of the visual system during the paradoxical phase of sleep in the cat. J. Physiol. 55, 305-306 (1963).

122. Datta S: Cellular basis of pontine ponto-geniculo-occipital wave generation and modulation. Cell Mol. Neurobiol. 17, 341-365 (1997).

123. Peigneux P, Laureys S, Fuchs S et al.: Generation of rapid eye movements during paradoxical sleep in humans. Neuroimage 14, 701-708 (2001).

124. Inoué S, Saha UK, Musha T: Spatio-temporal distribution of neuronal activities and REM sleep. In: Rapid Eye Movement Sleep. Mallick BN, Inoue S (Eds). Narosa Publishing, New Delhi, India 214-220 (1999).

125. Ioannides AA, Corsi-Cabrera M, Fenwick PB et al:: MEG tomography of human cortex and brainstem activity in waking and REM sleep saccades. Cereb Cortex 14, 56-72 (2004).
126. Lim AS, Lozano AM, Moro E et al.: Characterization of REM-sleep associated ponto-geniculo-occipital waves in the human pons. Sleep 30, 823-827 (2007).

127. McCarley RW, Winkelman JW, Duffy FH: Human cerebral potentials associated with REM sleep rapid eye movements: links to PGO waves and waking potentials. Brain Res. 274, 359-364 (1983).

128. Salzarulo P: Direct depth recording of the striate cortex during REM sleep in man: are there PGO potentials in EEG? Clin. Neurophysiol. 199-202 (1975).

129. Datta S: Avoidance task training potentiates phasic pontine-wave density in the rat: a mechanism for sleep-dependent plasticity. J. Neurosci. 20, 8607-8613 (2000).

130. Datta S, Li G, Auerbach S: Activation of phasic pontine-wave generator in the rat: a mechanism for expression of plasticity-related genes and proteins in the dorsal hippocampus and amygdala. Eur. J. Neurosci. 27, 1876-1892 (2008).

131. Ravassard P, Pachoud B, Comte JC et al.: Paradoxical (REM) sleep deprivation causes a large and rapidly reversible decrease in long-term potentiation, synaptic transmission, glutamate receptor protein levels, and ERK/MAPK activation in the dorsal hippocampus. Sleep 32, 227-240 (2009).

132. Karlsson MP, Frank LM: Awake replay of remote experiences in the hippocampus. Nat. Neurosci. 12, 913-918 (2009).

133. Foster DJ, Wilson MA: Reverse replay of behavioural sequences in hippocampal place cells during the awake state. Nature 440 , 680-683 (2006).

134. Hoffman KL, McNaughton BL: Coordinated reactivation of distributed memory traces in primate neocortex. Science 297, 2070-2073 (2002).

135. Peigneux P, Orban P, Balteau E et al.: Offline persistence of memory-related cerebral activity during active wakefulness. PLoS Biol. 4, E100 (2006).

\section{Affiliations}

- Anahita Shaffii-Le Bourdiec Cyclotron Research Centre, University of Liège, Belgium

Tel.: +32 43662306

Fax: +32 43662946

ashaffii@ulg.ac.be

- Vincenzo Muto

Cyclotron Research Centre, University of Liège, Belgium

Tel.: +32 43662306

Fax: +324366 2946

vincenzo.muto@ulg.ac.be

- Laura Mascetti

Cyclotron Research Centre, University of Liège, Belgium

Tel.: +32 43662306

Fax: +3243662946

lmascetti@ulg.ac.be

- Ariane Foret

Cyclotron Research Centre, University of Liège, Belgium

Tel.: +32 43662306

Fax: +32 43662946

aforet@ulg.ac.be

- Luca Matarazzo

Cyclotron Research Centre, University of Liège, Belgium

Tel.: +32 43662306

Fax: +32 43662946

lmatarazzo@ulg.ac.be

- Caroline Kussé

Cyclotron Research Centre, University of Liège, Belgium

Tel.: +32 43662362

Fax: +32 43662946

caroline.kusse@gmail.com

- Pierre Maquet

Cyclotron Research Centre (B30),

University of Liège, Allée du 6 Août, 4000 Liège, Belgium

Tel.: +32 43663687

Fax: +32 43662946

pmaquet@ulg.ac.be 